PALAVRA ABERTA /

FREE SPEECH 
http://dx.doi.org/10.1590/0102-4698145380

\section{IMAGENS DA DOCÊNCIA}

Eliane Marta Teixeira Lopes*

- Mas - dirás tu - como é que podes discernir a verdade daquele tempo, e exprimi-la depois de tantos anos?

Ab! Indiscreta! Ignorantona! Mas é isso mesmo que nos faz senhores da Terra, é esse poder de restaurar o passado, para tocar a instabilidade de nossas impressões e a vaidade de nossos afetos. Deixa lá dizer Pascal que o homem é um caniço pensante. Não; é uma errata pensante, isso sim.

Cada estação da vida é uma edição, que corrige a anterior, e que será corrigida também, até a edição definitiva, que o editor dá de graça aos vermes.

(ASSIS, 1997, p. 69)

A partir de um convite, foi como se uma brecha tivesse sido aberta na minha mente; por ela saíram lembranças e entraram recordações.

lembrar é reproduzir espontaneamente na memória recordar fazer esforço para que a memória reproduza

EU ME LEMBRO, mas, também, EU ME RECORDO do que LEMBRAM POR MIM.

EU ME LEMBRO de que aprendi a ler na "idade certa", na cartilha da Lili. Lili olhava para mim enquanto pedia que eu olhasse para ela: "Olhem para mim, eu me chamo Lili".

Lili, loura como minha mãe e minha irmã e como diziam que os anjos eram, viu uma menina de franja, cabelos castanhos, curtos, lisos e escorridos, ávida por aprender a ler e ter uma amiga. Quando a professora anunciou que a sala receberia uma menina, a menina que eu era pensou que ela chegaria em carne e osso, sangue e sentimentos para ser sua amiga. $\mathrm{O}$ cartaz de papel à sua frente foi minha primeira grande decepção com o mundo das letras. Outras viriam.

EU ME RECORDO do que LEMBRAM POR MIM

Os professores sempre ocuparam lugar especial em minha memória. A começar pela

*Doutora em Educação pela Pontifícia Universidade Católica de São Paulo (PUC-SP). Professora Emérita da Universidade Federal de Minas Gerais (UFMG). Professora Visitante do Programa de Pós-Graduação em Educação da Universidade Federal de Ouro Preto (ICHS-UFOP). E-mail: emtlopes@uai.com.br. 
primeira e inesquecivel dona Alice Thompson Flores, no primeiro ano do Curso Primário do Colégio Batista, no Rio de Janeiro. Ela foi em grande parte responsável por en ter adquirido o prazer de estudar, de ler, de aprender. Seguiram-se dona Ondina (segunda série), dona Regina (terceira), dona Ligia (quarta) e dona Elvira (quinta). Há alguns anos, numa roda de amigos, falávamos sobre antigos professores. Fui o único que lembrou os nomes de todas as professoras do Primário, de muitos do Ginásio, de alguns do Científico. O fato de ter permanecido no mesmo colégio, do primeiro ano do Primário ao terceiro do Cientifico, talvez explique essa memória. O cenário era o mesmo: os velhos prédios, os pátios de recreio, as fugas pelo rio Trapicheiro, as expediçoes no bosque que subia a colina. (AIRTON RIBEIRO)

EU ME LEMBRO de que dona Lucy tinha cabelos pretos, curtos, anelados. Não sei se era, mas pensava que era gordinha ou talvez por se parecer com minha prima Martha Maria... Usava saia justa e blusa justa também escondendo os fartos seios. Não me lembro de sua voz, mas me lembro de infindáveis cópias e ditados e leitura em voz alta, que, como veem, me é útil até hoje. Eu tinha muito medo de fracassar... Ler era coisa de gente grande, jornais e revistas, livros com imagens e sem imagens, e eu era ainda pequena, metida em um uniforme, com blusabranca (nem sempre muito limpa) e veste azul marinho na qual era ostentada um distintivo com uma tocha acesa e os dizeres: conhece o dever e cumpre-o.

\section{EU ME RECORDO do que LEMBRAM POR MIM}

Por definição minha, perseguindo respostas, eu desconfiava ser a escola um lugar de muito
respeito. Era preciso ter as unhas limpas e aparadas, cabelo penteado, acervo caprichado
dentro do embornal, uniforme lavado - calca azul-marinho e camisa de fustão branco-e
passado com ferro de brasa, goma de polvilho rala na gola, para não arranbar o pescoço.
A professora, quando os alunos ainda na fila e do lado de fora da sala, lia a gente
como se fosse um livro. E mãe nenhuma gostaria de ser chamada de desmazelada pela
mulher mais respeitada do lugar. (QUEIRÓS, 1996, p. 10, 11)

EU ME LEMBRO de ter sido muito difícil entender o que queriam de mim. Quando estudei geometria havia quase cem teoremas, mas nunca me explicaram - ele se chamava professor Leopoldo, e às vezes sentíamos cheiro de cachaça em seu hálito - o que era geometria, mesmo que dissessem que era um conhecimento muito antigo, dos tempos dos faraós do Egito (ah! sim! O Egito povoava meus sonhos de viajar um dia, mas o que tinha a ver uma coisa com a outra?). $\mathrm{O}$ que queria ele de mim? O que queriam de mim cada um dos 50 professores que tive na vida? As ordens e os significantes foram se acumulando, desencontradamente, desde o Jardim de infância até a universidade quando o muxoxo tomou o lugar da angústia. Senta direito, não se pega assim no lápis, caneta tinteiro borra, decore a tabuada, 
a de 9 é a mais difícil, moça, não senta de pernas abertas, presta a atenção, venha ao quadro negro, copie esta frase 100 vezes, ditado, next next next, os donatários das capitanias hereditárias, Yes, I do, merci, au revoir, rosa rosae rosam, amanhã tem prova, genitivo,nominativo, ablativo, ativo, acusativo, o Brasil é uma terra de amores alcatifada de flores, minha terra tem palmeiras onde canta Elis Regina, carrot, lettuce, La table est servie, the book is on the table,leia, escreva, faça as contas, cálculos mentais, a capital do Nepal é Katmandu.

Por que é que sempre explicam as coisas e não as palavras?

\section{EU ME RECORDO do que LEMBRAM POR MIM}

Que querias tu, afinal, meu velho mestre de primeiras letras? Lição de cor e compostura na aula; nada mais, nada menos do que quer a vida, que é das últimas letras; com a diferença que tu, se me metias medo, nunca me meteste zanga. Vejo-te ainda agora entrar na sala, com as tuas chinelas de couro branco, capote, lenço na mão, calva à mostra, barba rapada; vejo-te sentar, bufar, grunhir, absorver uma pitada inicial, e chamar-nos depois à lição. E fizeste isto durante vinte e três anos, calado, obscuro, pontual, metido numa casinha da Rua do Piolho, sem enfadar o mundo com a tua mediocridade, até que um dia deste o grande mergulho nas trevas, e ninguém te chorou, salvo um preto velho, - ninguém, nem eu, que te devo os rudimentos da escrita. (ASSIS, 1997, p. 41)

EU ME LEMBRO DE que dona Marlene era também morena e tinha cabelos anelados... era bonita e muito jovem apesar de ser dona - todas as mulheres, com exceção de minhas amigas, as empregadas domésticas e eu eram donas. Só soube que naquela época era jovem quando a encontrei na faculdade, fazendo curso de jornalismo e eu, pedagogia. Eu era, então, mais velha do que ela era quando foi minha professora na terceira série do curso primário. Para enfeitar o passado, posso dizer que ela pressentia em mim uma escritora que ainda hoje tento ser, mas nunca me deixou escrever diálogos entre abóboras e pimentões, pois, me ensinou ela, legumes não falam, esquecendo-se, talvez, da lição de metáforas, mas me enquadrando direitinho.

\section{EU ME RECORDO do que LEMBRAM POR MIM}

A professora gostava de vestido branco, como os anjos de maio. Carregava sempre um lenco dobrado dentro do livro de chamada ou preso no cinto, para limpar as mãos, depois de escrever no quadro negro. Paninho bordado com flores, pássaros, borboletas. Ela passava o exercício, e de mesa em mesa ia corrigindo. Um cheiro de limpeza coloria o ar quando ela passava. Sua letra, como era bem desenhada, amarradinha uma na outra! Parecia com a do ramalhete espiritual oferecido à Dona Orozina pelo seu aniversário. Redonda, fácil de decifrar, sem sair da linha, como se aprendida depois do borizonte. (QUEIRÓS, 1996, p. 44) 
EU ME LEMBRO DE que meu pai contava dos castigos que havia sofrido na escola primária com as orelhas de burro. Senti medo quando fiquei certa vez no canto da parede, fazer medo a uma criança equivale a um atentado terrorista: ela não sabe de onde nem quando virá e nada pode fazer. Senti medo e tédio quando fiquei de castigo, sozinha em sala olhando pela janela os que estavam no pátio, e mais uma vez desafiando, sem saber que estava, e não fazendo o mandado. A solidão não corrige, estimula o malfeito e o malfeitor. Minha prima estudava em colégio de freiras, de irmãs, oui ma mère, non ma soeur, e quando se deitava, ou ia ao banheiro ou pensava, sabia que o olho de Deus a vigiava e todos os seus malfeitos seriam punidos - nem que fosse mesmo na hora da morte, depois do que a esperaria o inferno. James Joyce (DEDALUS, 1914) a qualquer propósito era punido com três dias de silêncio no refeitório e pancadas com palmatória. Claudine, porque ria, tinha de fazer 100 cópias em cursiva do verbo rir (COLETT'TE, 1900).

\section{EU ME RECORDO do que LEMBRAM POR MIM}

Ó palmatória, terror dos meus dias pueris(...) com que um velho mestre, ossudo e calvo, me incutiu no cérebro o alfabeto, a prosódia, a sintaxe, e o mais que ele sabia, benta palmatória, tão praguejada dos modernos, quem me dera ter ficado sob o teu jugo, com a minha alma imberbe, as minhas ignorâncias, e o meu espadim, aquele espadim de 1814, tão superior à espada de Napoleão! (ASSIS, 1997, p. 41)

Palmatória ainda é usada como punição corporal em 20 Estados norte-americanos. Mais de 220 mil crianças foram alvo de punições desse tipo entre 2005 e 2006.

Todos os anos, os Legislativos estaduais dos Estados Unidos debatem se a punição corporal é uma forma arcaica de violência contra a criança ou o adolescente, ou um meio eficaz de disciplina. Isso porque ainda existem 20 Estados norte-americanos que utilizam a palmatória (um artefato, na maioria das vezes, feito em madeira, com uma haste e uma chapa na ponta) para punir estudantes indisciplinados. (GUIA DO ESTUDANTE)

EU ME LEMBRO DE nunca ter apanhado de qualquer professor ou professora, mesmo se em casa as palmadas vigorassem. Acho uma curiosidade altamente reveladora que em português o castigo físico aplicado na bunda das crianças por adultos leve o nome do instrumento que o aplica: a palma da mão dá palmada!

Em francês, o mesmo gesto fessée leva o nome do lugar em que o castigo é aplicado, Fesse.

\section{EU ME RECORDO do que LEMBRAM POR MIM}

COMO MADEMOISELLE Lambercier tinha por nós a afeição de uma mãe, tinha também a autoridade, e às vezes a levava ao ponto de, quando mereciamos, 
nos infligir a punição de filhos. Por um bom tempo ela ficou só na ameaşa, e a mim essa ameaça de um castigo totalmente novo me parecia apavorante; mas, depois da execucão, achei-o menos terrivel do que a própria espera: e o que há de mais estranho é que aquele castigo me fez criar ainda mais afeição por aquela que me o impôs. Era preciso mobilizar toda a verdade dessa afeição e toda a minha docilidade natural para impedir-me de procurar de volta o mesmo tratamento fazendo por merecê-lo; pois en encontrei na dor, na própria vergonha, uma mistura de sensualidade que me deixon pleno mais de desejo do que de temor de experimentá-lo de novo, pela mesma mão. (ROUSSEAU)

Não poupes ao menino a correção: se tu o castigares com a vara, ele não morrerá; castigando-o com a vara salvarás sua vida da morada dos mortos.

(Provérbios 23: 13-14)

EU ME LEMBRO DE fazer composições a partir de quadros com "cenas": meninos e meninas em torno de alguma coisa, cuidando da horta, um cachorro ou mais correndo atrás de galinhas... Exercícios de imaginação postos no papel por obrigação, pobres como costuma ser a imaginação obrigatória.

EU ME RECORDO do que LEMBRAM POR MIM

- O que me diz esse quadro que a professora

inimiga/amiga

ostenta

cultivando no menino

a sua escrita primária

e aflorando no adulto

sua fúria imaginária?

- O que quer de novo a mestra

com o álbum de falsas fábulas

frente ao velho adolescente

contido

nas calças de seu desejo

como desatento

- menino tido

com as asas de seus

olhos

brincando no verde vento?

(SANT'ANNA, 1978)

EU ME LEMBRO DE muitas professoras, de muitos professores - em torno de 50, já disse - e dos que me esqueci? Por isso chamo 
e acho na literatura minha emoção. Emoção de aluna tornada professora à força de não querer. Simone era professora de uma escola particular da capital frequentada principalmente por filhos de adultos inteligentes, atuantes e bem-nascidos. As festas de fim de ano frequentadas por pessoas das famílias das crianças eram cheias de surpresas e muita alegria - afinal, era o fim do ano letivo. Outra série, outra/os professores, algumas vezes outra escola. E eu participando de toda a alegria, fui despedir-me e agradecer à professora, tínhamos tido um convívio bacana durante o ano, eu como avó/pedagoga/professora da pós. Mas encontrei-a chorando, emocionada, e ouvi-a dizer: sabe, todo ano é isso. A gente se despede da convivência que teve dia a dia com eles, ensinando, aborrecendo, rindo e brincando junto... Sabe, é muito duro, todo ano despedir-se e começar tudo novamente. Não, Simone, a professora da PG não sabia.

\section{EU ME RECORDO do que LEMBRAM POR MIM}

Ninguém tinha maior paciência, melhor sabedoria, mais encanto. E todos gostavam de aprender primeiro, para fazế-la feliz. Eu, como já sabia ler um pouco, fingia não saber e aprendia outra vez: Na hora da chamada, o silêncio ficava cada vez mais vazio e o coração quase parado, esperando a vez de responder "presente". Cada um se levantava, em ordem alfabética, e com voz, alta, clara, vaidosa, marcava sua presença e recebia mais uma bolinha azul na frente do nome. (...). O giž, em sua mão, mais parecia um pedaço de varinha mágica de fada, explicando os mistérios. E, se economizava o quadro, para caber todo o ponto, nós também aproveitávamos bem as margens do caderno, escrevendo nas beiradinhas das folhas. Não acertando os deveres, Dona Maria elogiava a letra, o raciocinio, o capricho, o aproveitamento do caderno. A gente era educado para saber ser com orgulho. Assim a nota baixa não trazia tanta tristeza. (...) Nas aulas de poesia, Dona Maria caprichava. Abria o caderno, e não só lia poemas, mas escrevia fundo em nosso pensamento as ideias mais eternas. (QUEIRÓS, 1996, p. 44, 45, 46)

Terão sido esses professores, professoras, formatados como queriam, querem as prescrições pedagógicas? Achei essas palavras de Paulo Freire e pus em papel para não ceder ao desejo de tudo esquecer:

"Acreditamos que a educação sozinha não transforma a sociedade, sem ela tampouco a sociedade muda. Se a nossa opção é progressiva, se estamos a favor da vida e não da morte, da equidade e não da injustiça, do direito e não do arbítrio, da convivência com o diferente e não de sua negação, não temos outro caminho senão viver a nossa opção."

Belo Horizonte, 15 de outubro de 2014. 


\section{REFERÊNCIAS}

ASSIS, Joaquim Maria Machado. Memórias póstumas de Brás Cubas. Porto Alegre: L\&PM, 1997. GUIA DO ESTUDANTE. Palmatória ainda é usada como punição corporal em 20 estados norteamericanos. Disponível em: <http://guiadoestudante.abril.com.br/vestibular-enem/ palmatoria-ainda-usada-como-punicao-corporal-20-estados-norte-americanos-624001. shtml>. Acesso em: 15 dez. 2014.

QUEIRÓS, Bartolomeu Campos. Ler, escrever e fazer conta de cabeça. Belo Horizonte: Editora Miguilim, 1996.

ROUSSEAU Jean-Jacques. Confissões. Disponível em: <http:// faroldahistoria1.blogspot. com.br/2010/08/palmadas.html>. Acesso em: 15 dez. 2014.

SANT'ANNA, Afonso Romano. O Burro, o Menino e o Estado Novo. In: LADEIRA, Julieta de Godoy (Org.). Lições de Casa. Exercícios de imaginação. São Paulo: Livraria Cultura Editora, 1978.

Recebido: 28/01/2015

Aprovado: 28/01/2015

Contato:

Universidade Federal de Minas Gerais Faculdade de Educação Av. Presidente Antônio Carlos, 6627 Pampulha Belo Horizonte | MG | Brasil CEP 31.270-901 
